\title{
Changes in soil carbon in hill-country under contrasting phosphorus fertiliser and sheep stocking rates
}

\author{
A.D. MACKAY, R. VIBART and C. McKENZIE \\ AgResearch Grasslands, Private Bag 11008, Palmerston North 4422, New Zealand \\ alec.mackay@agresearch.co.nz
}

\begin{abstract}
Carbon (C) measurements were analysed for soil sampled to two depths $(0-75$ and $75-150 \mathrm{~mm})$ in 2003 and again in 2014 in three of the farmlets of a long-term phosphorus $(\mathrm{P})$ fertiliser and sheep grazing experiment at the AgResearch Ballantrae Hill Country Research Station. The farmlets received either $125 \mathrm{~kg} /$ ha/year of single superphosphate (SSP) from 19751979 and none since (LFNF), or the same amount of SSP applied as for LFNF from 1975-1979 and $125 \mathrm{~kg}$ SSP/ha/year since 1980 (LFLF), or $625 \mathrm{~kg} / \mathrm{ha} /$ year of SSP applied from 1975-1979, and $375 \mathrm{~kg} \mathrm{SSP/ha/year}$ since 1980 (HFHF). Carbon concentration in soil at both sampling depths was not affected by differences in $\mathrm{P}$ fertiliser inputs and sheep stocking rate, but there were significant $(\mathrm{P}<0.001)$ slope $\mathrm{x}$ farmlet and aspect $\mathrm{x}$ farmlet interactions. Data from this long-term study provide science, policy and industry with invaluable insights into the changes in soil $\mathrm{C}$ stocks in pastoral hill-country soils.
\end{abstract}

Keywords: carbon stocks, fertiliser, sheep grazing, pasture production, long-term experiment

\section{Introduction}

Beef + Lamb NZ recently launched their Environment Strategy, which lays out a progressive long-term vision for the sector based on four priority areas - healthy productive soils, thriving biodiversity, clean water and reducing carbon (C) emissions (available at https:// beeflambnz.com/environment-strategy). The Labourled Government has announced its first steps towards making New Zealand C neutral by 2050 (available at https://www.newshub.co.nz/home/politics/2017/12/ government-plans-to-go-carbon-neutral-by-2050. $\mathrm{html})$. An interrelated question is: should soil $\mathrm{C}$ be included in the budget as the feasibility of a $\mathrm{C}$ neutral economy by 2050 is explored? Carbon stored in soil organic matter is an important reservoir within the global C cycle (Lal 2004). For example, a 5\% increase in $\mathrm{C}$ stored in the $0-2 \mathrm{~m}$ soil layer could potentially reduce atmospheric $\mathrm{CO}_{2}-\mathrm{C}$ by $16 \%$. The ability to reduce atmospheric $\mathrm{CO}_{2}-\mathrm{C}$ by this magnitude would offer an option for mitigating greenhouse gas emissions from farm systems, and would be of immediate interest to individual landowners, industry and government.
The challenge is understanding what practices could result in a sustained increase in the amount of $\mathrm{C}$ sequestered, and equally important, identifying the practices that place the current stocks of $\mathrm{C}$ at risk of depletion. The latter is also of interest to producers because of the pivotal role soil organic matter plays in the provision of a wide range of services (e.g. food, support, filtering, water regulation) from our pastoral soils (Dominati et al. 2010). Soil erosion from hill slopes represents the greatest risk to C stocks in hillcountry (Lambert et al. 1984). This paper reports on changes in soil $\mathrm{C}$ between 2003 and 2014, from two soil depths $(0-75$ and $75-150 \mathrm{~mm})$ on three slope positions and aspects, within three of the farmlets of the longterm $\mathrm{P}$ fertiliser and sheep-grazing experiment, located at the AgResearch Ballantrae Hill Country Research Station (Lambert et al. 2000).

\section{Materials and methods \\ Study site}

The Ballantrae Research Station is located in southern Hawkes Bay (408180S 1758500E), New Zealand, 300 $\mathrm{m}$ a.s.l. with an average air temperature of $12.8^{\circ} \mathrm{C}$ and an annual rainfall of $1270 \mathrm{~mm}$. The soils are classified as Andosols and Luvisols with a silt-loam texture (Lambert et al. 2000).

\section{Experimental farmlets}

Three farmlets were sampled as part of the present study, including one which received an average 125 $\mathrm{kg} / \mathrm{ha} /$ year of single superphosphate (SSP) from 19751979 and none since then (LFNF), one with the same amount of SSP applied from 1975-1979 as for LFNF and $125 \mathrm{~kg} \mathrm{SSP} / \mathrm{ha} /$ year applied subsequently (LFLF), and one which received an average $625 \mathrm{~kg} / \mathrm{ha} /$ year of SSP applied from 1975-1979 and $375 \mathrm{~kg} \mathrm{SSP} / \mathrm{ha} /$ year applied subsequently (HFHF).

The farmlets have been continuously grazed predominantly with breeding ewes since 1975 . Stocking rates had been 6.0 stock units (SU)/ha on all farmlets before 1975, where a stock unit is defined as a breeding-ewe-plus-single lamb equivalent consuming $550 \mathrm{~kg}$ dry matter (DM)/year. From 1976 until the present time, the stocking rate has increased to 10.6 $\mathrm{SU} / \mathrm{ha}$ on the LFLF and has been as high as $16 \mathrm{SU} / \mathrm{ha}$ on the HFHF pasture. The stocking rate at LFNF has 
slowly dropped from 10.6 to about $6.0 \mathrm{SU} /$ ha, the preexperimental value before 1975 (Mackay \& Lambert 2011).

\section{Soil sampling and analysis}

On each farmlet, soils were sampled to two depths (0-75 and 75-150 mm) in September 2003 and 2014. Within each farmlet, soil samples were taken from the 18 permanently marked sites established in 1975 . The permanent sites cover three slope positions [low $\left(1-12^{\circ}\right)$, medium $\left(13-25^{\circ}\right)$, and high $\left.\left(>25^{\circ}\right)\right]$, and three aspects (centred on East, Southwest and Northwest). Two replicate sampling sites were used within each slope and aspect class combination within each farmlet. At each of the resultant 18 sites within each farmlet, 20 soil cores $(2.5 \mathrm{~cm}$ diameter $)$ were collected and bulked for analysis of soil C concentration. A single separate set of soil samples were taken using stainless steel rings (10 $\mathrm{cm}$ diameter) from each depth to determine bulk density at both sampling dates.

Soil samples were air-dried and passed through a 2 $\mathrm{mm}$ sieve. Each sample was mixed thoroughly and a subsample analysed for total carbon concentration (\%) using a Leco CNS-2000 dry combustion analyser. This involved combustion at $1350^{\circ} \mathrm{C}$ followed by detection of combustion gas (as $\mathrm{CO}_{2}$ ) using infrared absorption measurement. For bulk density, the soil samples in the cores were dried at $105^{\circ} \mathrm{C}$ for $36-48 \mathrm{~h}$, and then weighed.

To quantify total $\mathrm{C}$ stocks/ha, soil C concentrations were multiplied by the bulk density measures from each site to obtain tonnes of $\mathrm{C}$ per hectare ( $\mathrm{t} / \mathrm{ha}$ ) and a weighted average for a farmlet was determined to account for the percentage of land in each of the slope and aspects classes. Across the three farmlets, the percentage of the land in low, medium and high slope positions ranged from $19-27 \%, 46-59 \%$ and $23-28 \%$, respectively. The percentage of each farmlet facing SW was similar (17-29\%), but there were differences in the percentage facing E (19-60\%) and NW (26-50\%).

\section{Statistical analysis}

A nested analysis of variance (nested ANOVA) was conducted to compare the effects of slope (Low, Medium and High) and aspect (Southwest, East and Northwest) for each year (2003 and 2014) within each farmlet (a unique combination of phosphorus fertiliser inputs and sheep stocking rate). Fishers Least Significant Differences post-hoc test was used to compare differences between means. The analyses were conducted using Genstat $18^{\text {th }}$ edition (VSN International Limited). Means were considered significantly different at $\mathrm{P}<0.05$ (with smaller values providing stronger evidence of significance) and P-values $\geq 0.05$ but $<0.10$ were considered a trend.

\section{Results}

The concentrations of soil $\mathrm{C}$ within the $0-75 \mathrm{~mm}$ and $75-150 \mathrm{~mm}$ soil depths in both 2003 and 2014 were not influenced by differences in the P fertiliser history and sheep stocking rate treatments (farmlets). Because of the lack of farmlet replication data to explore the other two main effects (slope and aspect) independently (and hence the need of a nested ANOVA), the significance of slope and aspect as interaction effects were explored. There were significant $(\mathrm{P}<0.001)$ slope $\mathrm{x}$ farmlet (Figure 1) and aspect $\mathrm{x}$ farmlet (Figure 2) interactions. Within the $0-75 \mathrm{~mm}$ soil depth, $\mathrm{C}$ concentration in soil on the low slope $(6.01 \pm 1.28 \%)$ was $40 \%$ higher than on the high slope $(4.28 \pm 0.85 \%)$ in the majority of sites sampled across all three farmlets in both years (Figure 1). Similarly, within the $75-150 \mathrm{~mm}$ soil depth C concentration in soil on the low slope $(4.32 \pm 0.99 \%)$ was $29 \%$ higher than on the high slope $(3.35 \pm 0.64 \%)$ across the majority of sites in all three farmlets in both years (Figure 1). Carbon concentrations in soil on the medium slopes were similar to those of the low slopes in the LFLF farmlet, but distinctly different in the other two farmlets.

Carbon concentrations in soil on the SW $(5.53 \pm 1.19 \%)$ and $\mathrm{E}(5.56 \pm 1.49 \%)$ aspects were $18 \%$ higher than on the NW (4.70 $\pm 0.84 \%)$ aspect within the $0-75 \mathrm{~mm}$ soil depth in the majority of sites across farmlets in both years (Figure 2). Similarly, soil C concentrations on the SW $(4.36 \pm 0.97 \%)$ and $\mathrm{E}(4.19 \pm 0.87 \%)$ aspects were $30 \%$ higher than on the NW $(3.27 \pm 0.64 \%)$ aspect within the 75-150 $\mathrm{mm}$ soil depth across most sites in all three farmlets in both years (Figure 2). The exception was with the HFHF farmlet where differences in soil C concentrations between aspects were small.

Total C stocks/farmlet, when adjusted for slope and aspect classes and averaged for the two sampling dates, were $30.9( \pm 1.0), 30.9( \pm 1.4)$ and $33.7( \pm 1.6)$ t/ha within the $0-75 \mathrm{~mm}$ soil depth in the LFNF, LFLF and HFHF farmlets, respectively. Corresponding values increased to $61.8( \pm 1.8), 60.0( \pm 1.0)$ and $62.6( \pm 1.4)$ t/ha when sampling was extended to $0-150 \mathrm{~mm}$.

\section{Discussion}

It was not possible to separate the distinct effects of $\mathrm{P}$ fertiliser application and sheep stocking rate on soil $\mathrm{C}$ concentrations and stocks, given the farmlet experimental design. Notwithstanding this limitation, this long-term experiment provides, with the level of control over inputs and ongoing monitoring, a unique resource for examining changes in the biology, chemistry and physical properties of the soil, pastures and livestock under contrasting $\mathrm{P}$ fertiliser and sheep stocking management.

Estimates of annual pasture production obtained on the moderate slope in 2015-2016 were 6917, 9708 


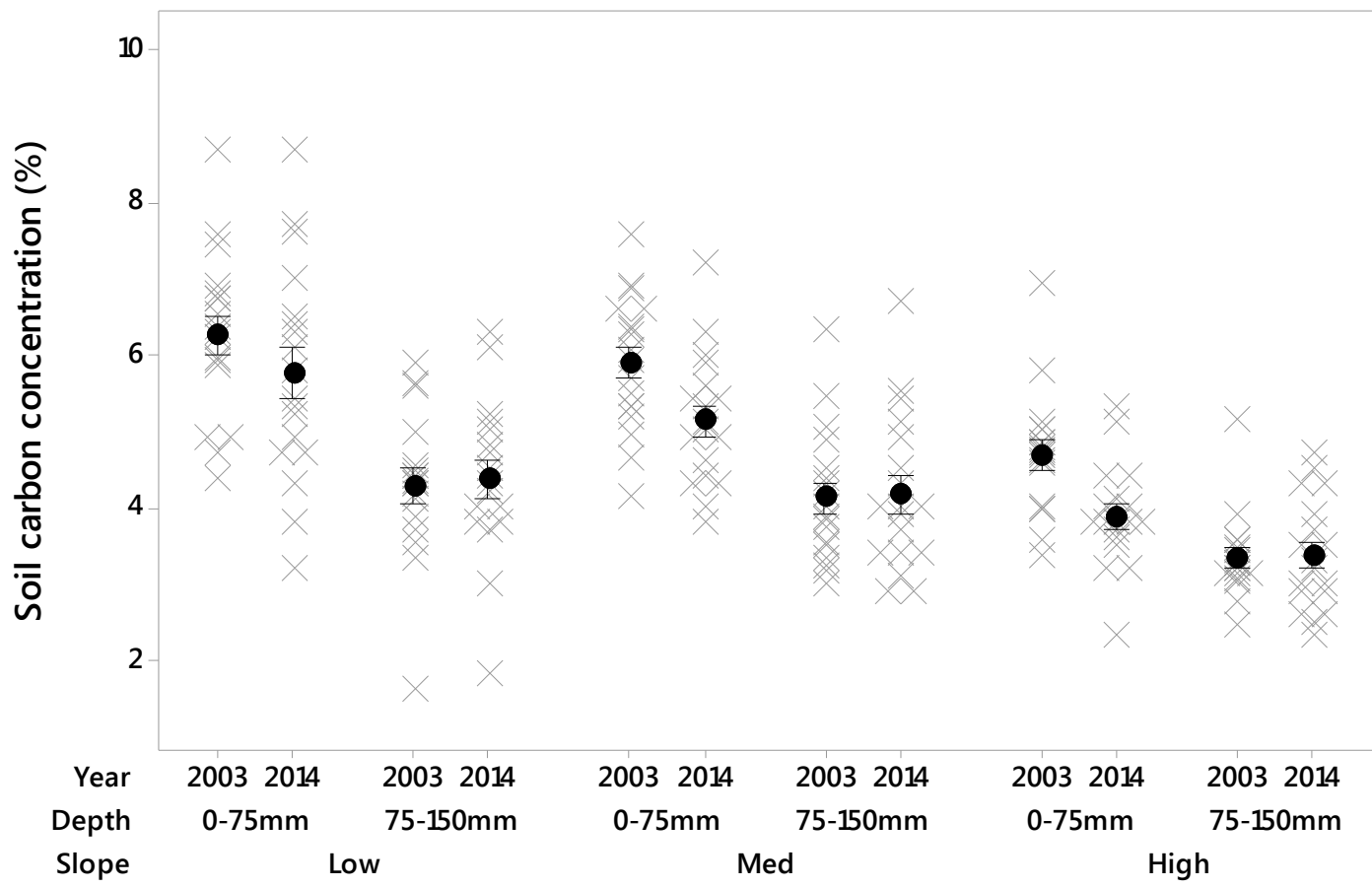

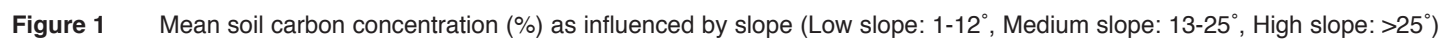
and soil depth (0-75 and 75-150 mm) across the LFNF, LFLF and HFHF farmlets in 2003 and 2014. Bars are one standard error from the mean.

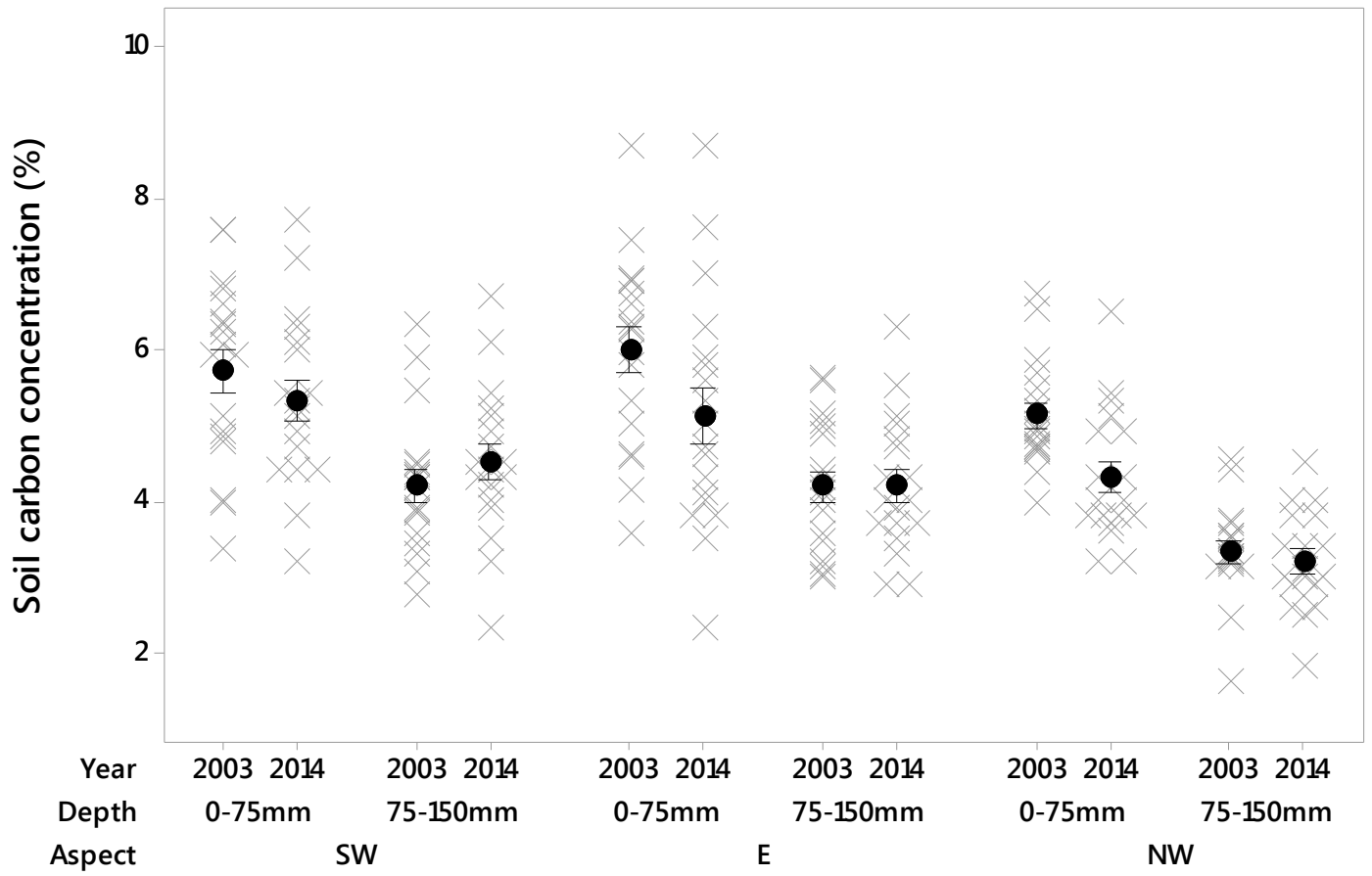

Figure 2 Mean soil carbon concentration (\%) as influenced by aspect (SW Southwest, E East, NW Northwest) and soil depth (075 and $75-150 \mathrm{~mm}$ ) across the LFNF, LFLF and HFHF farmlets in 2003 and 2014. Bars are one standard error from the mean. 
and $11289 \mathrm{~kg} \mathrm{DM} / \mathrm{ha}$ on the LFNF, LFLF and HFHF, respectively, which highlights the marked differences in primary production between the farmlets (Mackay et al. 2016). Currently, nominal sheep stocking rates are 50 and $120 \%$, higher on the LFLF (10.6 SU/ha) and HFHF (16 SU/ha), than LFNF (6 SU/ha) farmlet. The LFNF farmlet is best described now as a low fertility (Olsen $6 \mu \mathrm{g} / \mathrm{ml}$ ), extensive system (6 SU/ha), which would be unable to rear replacements to satisfactory liveweights under commercial farming practice. Notable parts of the medium and high slope areas of this farmlet are poorly grazed by the sheep. At the other end of the spectrum the HFHF system represents a high fertility soil (Olsen $\mathrm{P}>50 \mu \mathrm{g} / \mathrm{ml})$, intensive livestock system (16 SU/ha). Under commercial practice annual fertiliser application rate would be reduced.

Despite these diverse biological systems, soil C concentrations within the $0-75 \mathrm{~mm}$ and $75-150 \mathrm{~mm}$ depths were not influenced by the contrasting $\mathrm{P}$ fertiliser inputs and sheep stocking rate of the three farmlets. Total $\mathrm{C}$ stocks when adjusted for slope and aspect in each farmlet, were $30.9,30.9$ and $33.7 \mathrm{t} /$ ha in the $0-7.5 \mathrm{~cm}$ soil depth in the LFNF, LFLF and HFHF farmlets, respectively, averaged across the two sampling dates, increasing to $61.8,60.0$ and $62.6 \mathrm{t} / \mathrm{ha}$, respectively, when sampling was extended to $0-150 \mathrm{~mm}$. The absence of any differences in soil $\mathrm{C}$ stocks across the farmlets is consistent with previous findings at Ballantrae (Lambert et al. 2000), Whatawhata (Schipper et al. 2011), Winchmore (Condron et al. 2012) and Te Kuiti (Ghani et al. 2003). The simple explanation is that as primary production increases, associated losses also increase. Saggar et al. (1997) examined the partitioning and translocation of photosynthetically fixed ${ }^{14} \mathrm{C}$ in a grazed hill pasture at Ballantrae, and showed that while more of the $\mathrm{C}$ assimilated in the low fertility pasture was translocated below ground, a high fertility pasture assimilated more total $\mathrm{C}$ and translocated more $\mathrm{C}$ below ground to roots. The increased $\mathrm{C}$ translocation below ground in a high fertility system did not translate into increased soil $\mathrm{C}$ stocks, indicating higher turnover. A recent study by Schon et al. (2018) showed that earthworm abundance in the HFHF farmlet $(428 \pm 43$ / $\mathrm{m}^{2}$ ) was nearly twice that of the LFNF farmlet (219 \pm $36 / \mathrm{m}^{2}$ ). This suggests that if more litter and dung is available to sustain a larger biological community, then that community ingests greater amounts of plant and root biomass, with little change in soil C stocks.

Lambert et al. (2000) reported an overall mean reduction in annual soil $\mathrm{C}$ stock $(-1.7 \pm 0.4 \mathrm{t} \mathrm{C} / \mathrm{ha})$ to a depth of $0-75 \mathrm{~mm}$ in the same long-term $\mathrm{P}$ fertiliser and sheep grazing study from 1972 to 1987 . Linking the findings of the current study with those earlier measures of soil $\mathrm{C}$ from the farmlets, the trend for declining soil C from 1975 to 1987 is no longer apparent, despite the continuing divergence in the biological performance of the three farmlets. The findings of the current study are consistent with the findings from the Whatawhata $\mathrm{P}$ fertiliser and sheep grazing study (Schipper et al. 2011) from 1989 to 2006, but not from 1983 to 1989 when soil C stocks had increased. Current findings are also inconsistent with the findings of Schipper et al. (2014) who reported an average annual increase in soil $\mathrm{C}$ of $0.7 \pm 0.3 \mathrm{t} / \mathrm{ha}$ on 23 commercial farms over 30 years, and those of Parfitt et al. (2014) who reported an average annual increase in soil $\mathrm{C}$ of $1.3 \pm 1.0 \mathrm{t} / \mathrm{ha}$ on 19 commercial farms over 6 years. The factors contributing to the $\mathrm{C}$ sequestration rates reported by Schipper et al. (2014) and Parfitt et al. (2014) remain unclear. Like the sites in the long-term study at Ballantrae, the sites sampled by both Schipper et al. (2014) and Parfitt et al. (2014) were from stable locations, limiting the influence of recent erosion processes on $\mathrm{C}$ sequestration rates.

In contrast to management treatments, both slope (Figure 1) and aspect (Figure 2) had a pronounced influence on soil $\mathrm{C}$ concentrations and by default on $\mathrm{C}$ stocks across the farmlets. The differences in soil C with slope are likely to be the product of several factors, including differences in soil development and a wide range of biological processes from plant growth through to microbial activity, as they are influenced by the distinct soil moisture and temperature regimes found across different slope and aspect classes (Lambert \& Roberts 1978). The grazing animal transferring a disproportionate amount of the dung from medium and high slope to low slope positions (Saggar et al. 1990) potentially amplifies these differences. An understanding of the attributes of the landscape and the possible influence on livestock behaviours become important factors, when assessing the total soil C stocks in these landscapes.

The long-term $\mathrm{P}$ fertiliser and sheep grazing experiment at AgResearch Ballantrae Hill Country Research Station is an invaluable resource for exploring the long-term changes in hill pastoral systems. Data from the long-term experiment will contribute to the national inventory on soil C stocks in hill-country. New knowledge of the influence of slope position, aspect, phosphorus fertiliser inputs and grazing sheep on soil $\mathrm{C}$ inputs, losses and stocks will assist in refining the current protocols for sampling soil $\mathrm{C}$ stocks in hillcountry. The project provides science, policy and industry with further insights into the changes in soil C stocks in hill-country.

\section{ACKNOWLEDGEMENTS}

All the science, technical and farm staff and service staff that have being involved at the AgResearch Hill Country Research Station, Ballantrae since its establishment in 1972. The authors would like to 
recognise funding for the statistical analysis and preparation of the manuscript from Sustainable Land Management and climate change fund of the Ministry of Primary Industries and the AgResearch Strategic Science Investment Fund.

\section{REFERENCES}

Condron, L.M.; Black, A.; Wakelin, S.A. 2012. Effects of long-term fertiliser inputs on the quantities of organic carbon in a soil profile under irrigated grazed pasture. New Zealand Journal of Agricultural Research 55: 161-164.

Dominati, E.; Patterson, M.; Mackay, A. 2010. A framework for classifying and quantifying the natural capital and ecosystem services of soils. Ecological Economics 69: 1858-1868.

Ghani, A.; Dexter, M.; Perrott, K.W. 2003. Hot-water extractable carbon in soils: a sensitive measurement for determining impacts of fertilisation, grazing and cultivation. Soil Biology \& Biochemistry 35: 12311243.

Lal, R. 2004. Agricultural activities and the global carbon cycle. Nutrient Cycling in Agroecosystems 70: 103-116.

Lambert, M.G.; Roberts, E. 1978. Aspect differences in an unimproved hill country pasture II. Edaphic and biotic differences. New Zealand Journal of Agricultural Research 21: 255-260.

Lambert, M.G.; Trustrum, N.A.; Costall, D.A. 1984. Effect of soil slip erosion on seasonally dry Wairarapa hill pastures. New Zealand Journal of Agricultural Research 27: 57-64.

Lambert, M.G.; Clark, D.A.; Mackay, A.D.; Costall, D.A. 2000. Effects of fertiliser application on nutrient status and organic matter content of hill soils. New Zealand Journal of Agricultural Research 43: 127138.

Mackay, A.D.; Lambert, M.G. 2011. Long-term changes in soil fertility and pasture production under no, low and high phosphorus fertiliser inputs. Proceedings of the New Zealand Grassland Association 73: 37-42.

Mackay, A.D.; Costall, D.; Koolaard, J. 2016. Longterm phosphorus fertiliser and sheep grazing study: Monitoring in 2015-16. Report (RE500/2016/033) prepared for The Fertiliser Association of New Zealand Incorporated. 33 pp. http://www.fertiliser. org.nz/Site/research/completed_research/default. aspx

Parfitt, R.L.; Stevenson, B.A.; Ross, C.; Fraser, S. 2014. Changes in $\mathrm{pH}$, bicarbonate-extractable-P, carbon and nitrogen in soils under pasture over 7 to 27 years. New Zealand Journal of Agricultural Research 57: 216-227.

Saggar, S.; Mackay, A.D.; Hedley, M.J.; Lambert, M.G.; Clark, D.A. 1990. A nutrient transfer model to explain the fate of phosphorus and sulphur in a grazed hill country pasture. Agriculture, Ecosystems and Environment 30: 295-315.

Saggar, S.; Hedley, C.; Mackay, A.D. 1997. Partitioning and translocation of photosynthetically fixed ${ }^{14} \mathrm{C}$ fluxes in grazed hill pastures. Biology and Fertility of Soils 25: 152-158.

Schipper, L.A.; Dodd, M.B.; Fisk, L.M.; Power, I.L.; Paranzee, J.; Arnold, G. 2011. Trends in soil carbon and nutrients in hill-country pastures receiving different phosphorus fertilizer loadings for 20 years. Biogeochemistry 104: 35-48.

Schipper, L.A.; Parfitt, R.L.; Fraser, S.; Littler, R.A.; Baisden, W.T.; Ross, C. 2014. Soil order and grazing management effects on changes in soil $\mathrm{C}$ and $\mathrm{N}$ in New Zealand pastures. Agriculture, Ecosystems and Environment 184: 67-75.

Schon, N.L.; Mackay A.D.; Gray, R.A. 2018. Longterm implications of soil fertility for soil biology in hill country pastures. New Zealand Journal of Agricultural Research (Submitted) 
